Disponível em

http://www.anpad.org.br/rac

RAC, Rio de Janeiro, v. 17, n. 6, art. 5, pp. 720-738, Nov./Dez. 2013

$(c)$ EY-No

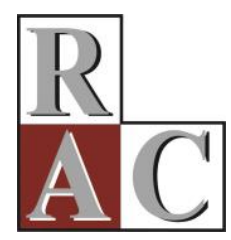

\title{
As Corporalidades do Trabalho Bailarino: Entre a Exigência Extrema e o Dançar com a Alma
}

\author{
Embodiment in Dance: Dancing with the Soul or Due to Extreme Demands
}

Dóris Dornelles de Almeida

E-mail: dornelles333@ hotmail.com Pontifícia Universidade Católica do Rio Grande do Sul - PPGAD/PUCRS

Av. Ipiranga, 6681, 90619-900, Porto Alegre, RS, Brasil.

Maria Tereza Flores-Pereira

E-mail: mtfpereira@terra.com.br Universidade Federal do Rio Grande do Sul - UFRGS Escola de Administração, Rua Washington Luiz, 855, 90010-460, Porto Alegre, RS, Brasil. 


\title{
Resumo
}

O contexto de desenvolvimento das pesquisas de corpo na Administração requer uma investigação que permita uma compreensão corporificada (não representacional) desse campo do conhecimento. Para isso, refletimos sobre estudos de corpo e corporalidades nos campos da Administração e da Dança (ballet), assim como informações de uma etnografia realizada em uma importante companhia de dança brasileira, a Dançar Companhia de Dança (nome fictício). O objetivo deste artigo é investigar como os bailarinos da Dançar corporificam (embody) seu trabalho bailarino. Apontamos para três importantes processos de corporificação do trabalho bailarino, quer sejam: a corporificação das dores e lesões, a corporificação de um tipo de corpo e de movimentação corporal e, por fim, a dificuldade de corporificar o dançar com a alma. Compreendemos que tais corporalidades se constituem a partir de um contexto mais amplo do que o da organização Dançar, pois incluem questões de hierarquia e disciplina, assim como composições sócio-histórico-culturais do campo da dança. Sob a perspectiva prática, analisamos que a exigência - organizacional e do campo da dança - por tais corporalidades acarreta tanto o uso extremo do corpo bailarino, quanto a vivência limitada da dança por esses trabalhadores artistas.

Palavras-chave: corpo; corporalidade (embodiment); trabalho bailarino; companhias de dança; etnografia.

\begin{abstract}
The context of research development in Management requires an investigation that allows an embodied (nonrepresentational) understanding of this field of knowledge. Thus, we reflect on studies on body and embodiment in the fields of Management and Dance (ballet), as well as information from an ethnographic study carried out in an important dance company called Dancing Dance Company (real name withheld). The objective of this article is to investigate how dancers of Dancing Dance Company embody their dance work. The study points out three important embodiment processes present in dancers' work in the dance company, which are: the embodiment of pain and injuries, the embodiment of a type of body and body movement, and, finally, the difficulty of embodying dancing from the soul. We understand that such corporalities are constituted from a wider context than the dance company environment since they include matters related to hierarchy and discipline as well as the socio-historical and cultural issues regarding the field of dance. From a practical perspective, we observed that demands that come either from the organization or from the field of dance have consequences, such as an extreme use of dancers' bodies as well as a limitation of the dance experience.
\end{abstract}

Key words: body; embodiment; dance work; dance companies; ethnography. 


\section{Introdução}

Temos como objetivo, neste artigo, investigar como bailarinos de uma grande companhia de dança brasileira corporificam (embody) seu trabalho bailarino. O termo embodiment - e suas variações embody, embodied - não foi ainda traduzido de forma consensual para a língua portuguesa, sendo empregado de forma variada pelos pesquisadores brasileiros (Flores-Pereira, 2010; Víctora, 1999). Escolhemos, para fins deste artigo, a nomenclatura da corporalidade (Eltz, 2011), assim como os termos corporificado(a), corporificam e corporificação para falar do processo de constituição das corporalidades.

Compreender os processos de corporificação e as corporalidades que se constituem a partir destes significa estudar a relação imbricada entre pessoa, corpo e mundo sócio-histórico-cultural (Merleau-Ponty, 2005). É uma perspectiva de estudo do social que parte de uma ontologia na qual a pessoa não é apenas uma mente, uma razão, uma subjetividade, pois ela (a pessoa) é o próprio corpo, um corpo pessoa (Flores-Pereira, 2010) que vive primeiramente em um mundo da prática e não da abstração (Csordas, 1990).

Para conhecermos esse mundo da prática, torna-se prioritária uma compreensão integrada da relação pessoa (pessoa corpo) e mundo, que se refere àquela que se estabelece antes do processo de racionalização e de organização da vida social, a partir de dicotomias (sujeito e objeto, corpo e mente, natureza e cultura). Busca-se, assim, compreender a relação imediata que as pessoas constituem com o mundo, gerando uma forma de conhecimento diferenciada daquela que busca compreender os processos de racionalização, abstração, simbolização das pessoas em relação à vida em sociedade.

Uma compreensão corporificada da vida social humana, desse modo, baseia-se na experiência corporal diária, no reconhecimento da noção de corpo como centro da experiência humana e no modo com que os corpos vivenciam os espaços sociais, inclusive o das organizações e do mundo do trabalho. Nesta pesquisa, buscamos focar na experiência corporal diária do bailarino no ambiente de uma importante companhia brasileira de dança, no intuito de se obter uma compreensão corporificada do trabalho bailarino.

Para isso, consideramos importante buscar um referencial teórico que: (a) reflita sobre os estudos de corpo e corporalidades no campo da Administração; (b) apresente o campo da dança, a partir de sua organização em companhias de dança; (c) destaque os modos pelos quais os bailarinos vêm vivenciando (corporalmente) seu trabalho bailarino.

$\mathrm{Na}$ parte empírica, focamos em informações de uma etnografia corporificada na Dançar Companhia de Dança (nome fictício). Nesse momento, direcionamos nosso olhar para os modos corporais de vivência do trabalho bailarino, buscando: (a) apontar as corporalidades mais presentes em tal trabalho artístico; (b) compreender o contexto a partir do qual tais corporalidades são constituídas; (c) analisar as implicações práticas de tais corporalidades na vida e no corpo de tais bailarinos. Nesse contexto, privilegiamos uma compreensão corporificada do mundo, assim como do campo da Administração.

\section{Corpo e Administração}

Áreas do conhecimento, como a Psicologia, a Educação, a Administração e até mesmo a Medicina, vêm buscando uma compreensão não biológica do corpo humano, no intuito de preencher uma lacuna na construção de seu conhecimento. Entretanto, é primordialmente na Antropologia que o corpo se constitui como um dado cultural, sendo o trabalho de Marcel Mauss, As técnicas do corpo, de 1934 (Mauss, 2003), aquele que inaugura esse campo de investigação. 
Desta publicação até os dias atuais, uma grande quantidade de pesquisas foi produzida na Antropologia, especialmente a partir de uma perspectiva de corpo como uma representação cultural. Uma importante representante dessa linha de pesquisa é a antropóloga Mary Douglas a qual considera a existência de dois corpos: o social e o físico (Douglas, 1970). A compreensão de Douglas é de que o corpo social condicionaria o modo pelo qual percebemos o corpo físico, concepção essa que aponta para um modo dicotômico de pensar a relação natureza e cultura, na qual a cultura - mais especificamente sua dimensão representacional - é algo que é anterior e desencadeador das práticas corporais, ou seja, a representação mental precede e orienta a prática do corpo.

Já no campo da Administração, um texto que se destaca é a tese publicada de Dale (2001). A autora apresenta como argumento inicial a ideia de que o corpo é uma presença ausente na teoria organizacional, pois mesmo não estando explicitado como sendo relevante para a disciplina, pressupostos específicos de corpo formaram (e ainda formam) a área dos estudos organizacionais. Os pressupostos dos quais a autora fala se referem a um ideal moderno-ocidental de separação da pessoa nas instâncias corpo e mente, sendo o corpo um objeto anatômico, normalizado, estruturado e ordenado a partir de uma lógica de partes, enquanto a mente torna-se instância mesma da pessoa, pois executa a valorizada capacidade de pensar e racionalizar.

O conhecimento que se desenvolve na Administração em conjunto com esse paradigma de corpo é aquele com ênfase na divisão (corpo e mente), na fragmentação (órgãos, sistemas) e na hierarquização (mente antecede e comanda o corpo). Mais do que isso, analisa Dale (2001), refere-se à produção de um conhecimento que enfatiza a produção de corpos, dos trabalhadores, por exemplo, normalizados, universais (masculinos, sem deficiências, brancos, magros, belos, etc.). Nesse contexto, a autora argumenta que, se o conhecimento no campo da Administração é primordialmente derivado desse modelo de corpo, torna-se necessário investigar outras construções de corpo (e pessoa) que permitam construir uma crítica, assim como outras modos de pensar e praticar o trabalho, as organizações, os negócios.

É nesse contexto que crescem os estudos de corpo não biológico no campo da Administração (Bahnisch, 2000; Barry \& Hazen, 1996; Harquail \& King, 2010; Hassard, Holliday, \& Willmott, 2000; Holliday \& Hassard, 2001; Kerfoot \& Knights, 1996; Küpers, 2005; Monaghan, 2002; Sinclair, 2005; Trethewey, 1999), inclusive no que se refere a publicações brasileiras em artigos em revistas científicas e capítulos de livros acadêmicos (Eccel, Grisci, \& Tonon, 2010; Flores-Pereira, 2010, 2012; Flores-Pereira, Cavedon, \& Davel, 2007; Matos, 1984; Pereira \& Ayrosa, 2012; Rosa \& Brito 2010). Sobre essas publicações nacionais, percebemos que, salvo estudos teóricos (Flores-Pereira 2010, 2012), o corpo vem sendo estudado como representação cultural.

Flores-Pereira Cavedon e Davel (2007) buscam obter uma compreensão simbólica do corpo humano nas organizações a partir de uma etnografia com os vendedores de uma livraria de shopping center. Os autores relacionam a cultura da competência e da agilidade no atendimento preconizada por tal livraria como algo desencadeador de algumas práticas corporais dos vendedores, no caso: o ficar em pé e o correr pela loja. Eccel, Grisci e Tonon (2010) estudam as representações de corpo no meio executivo a partir da análise de conteúdo de uma revista de negócios brasileira. Tais representações, analisam os autores, acabam por se materializar em prescrições oferecidas pela revista no sentido de adaptar esses corpos leitores ao modelo de sucesso profissional. Rosa e Brito (2010) defendem que as estruturas sociais se transformam em estruturas mentais para, posteriormente, serem (corporalmente) exteriorizadas "por reflexo, como um ato condicionado que o corpo executa instintivamente" (Rosa \& Brito, 2010, p. 208). Utilizam tal pressuposto para compreender as maneiras pelas quais a hierarquia e a disciplina são interiorizadas - moral e corporalmente - nos sujeitos militares. Por fïm, Pereira e Ayrosa (2012) em um estudo sobre a relação entre corpo e consumo gay carioca, também abordam o corpo pela perspectiva representacional. Para os autores, o corpo é uma "insígnia", sendo que aquele que o possui "controla, disciplina, domestica e aprisiona esse mesmo corpo", segundo os padrões estéticos da cultura gay (Pereira \& Ayrosa, 2012, p. 295).

Dessa maneira, percebemos que, apesar dos estudos de corpo no campo da Administração estarem ultrapassando a lógica anatômica, a centralidade dessas pesquisas é a compreensão do corpo 
como representação. Nessa perspectiva de estudo, a pessoa ainda é vista a partir de uma cisão, a qual demonstra uma antecedência da mente em relação ao corpo, pois é a representação (mente) que antecede e orienta a prática (corpo) cultural. $\mathrm{O}$ corpo segue sendo um objeto, não mais um objeto da ciência médica, mas, agora, um objeto da sociedade e da cultura. Os estudos brasileiros de corpo precisam avançar, abarcando também a perspectiva da corporalidade (embodiment), a qual vem sendo cada vez mais explorada nos estudos das Ciências Sociais, da Antropologia, assim como no campo dos estudos em Administração fora do Brasil (Dale, 2005; Flores-Pereira, Davel, \& Cavedon, 2008; Hindmarsh \& Pilnick, 2007; Sthyre, 2004; Yakhlef, 2010).

Assim, reforçamos nosso objetivo de investigarmos as corporalidades do trabalho bailarino. Buscamos, com isso, distanciar-nos de uma lógica dicotômica de construção do conhecimento, que preconiza uma separação entre mente e corpo, sujeito e objeto, representação e prática, na medida em que compreendemos a pessoa de modo indissociável de seu corpo - não mais um objeto - e do mundo sócio-histórico-cultural no qual habita. Nessa perspectiva, buscamos não trabalhar a partir da existência de uma sequência na qual a representação antecede a prática, uma vez que essa ideia mais uma vez separa e prioriza a mente (representação) em relação ao corpo (prática).

\section{Ballet, Companhias de Dança e o Trabalho Bailarino}

Nesta seção teórica, trabalhamos com a literatura do campo da dança no sentido de: (a) contextualizar a legitimação do ballet como dança espetáculo e sua difusão a partir de escolas e companhias de dança; (b) detalhar as relações que se estabelecem entre companhias de dança e bailarino a partir de um contexto mais amplo (campo do ballet).

\section{A dança ballet}

No período da Renascença, a arte da dança se constitui como espetáculo (Anderson, 1992; Au 1997; Minden, 2005; Sucena, 1989). O ballet, mais especificamente, foi concebido entre os séculos XVI e XVII como um "espetáculo das cortes europeias para santificar e glorificar o poder monárquico" (Thomas, 2003, p. 95).

Entre 1589 e 1610, mais de oitenta ballets foram criados nas cortes francesas somente para os homens dançarem, representando também papéis femininos. No reinado de Louis XIV (1643-1715), o Rei Sol, os ballets passaram a ser dançados pelo rei, representando oficialmente a dança no Estado. Nessa época, não havia palco, os bailarinos dançavam com roupas pesadas, máscaras, perto da plateia. Já em meados de 1830, Louis XV registrou um sistema de notação de movimentos, incluindo padrões de espaço, forma, musicalidade e estilo dos fundamentos do ballet (pés esticados, cinco posições dos pés e doze de braços) (Sasportes \& Ribeiro, 1991).

Embora o ballet tenha nascido nas cortes europeias, seu desenvolvimento deu-se nas primeiras escolas e companhias de dança por toda a Europa, por exemplo: Teatro do Rei, no bairro Haymarket em Londres (1705); Ballet Royal da Dinamarca, em Copenhagen (1726); Royal Opera no Covent Garden, em Londres (1732); Nápoles (1737) e Milão (1778), na Itália; Viena, na Áustria (1748); Stuttgart (1750) e Munique (1752), na Alemanha; Moscou (1776) e São Petersburgo (1783), na Rússia (Kraus, Hilsendager, \& Dixon, 1969). Estas seguiam regras rígidas de conduta dominantes na atividade artística por toda a Europa e envolviam professores de ballet, coreógrafos e ensaiadores.

Festividades nos moldes do ballet de corte europeu se iniciaram no Brasil em 1817. O casamento de D. Pedro e D. Leopoldina incluíram bailados coreografados pelo francês Luis Lacombe no Teatro Real (Sucena, 1989). No começo do século XIX, ocorreu no Brasil a apresentação da primeira companhia de ballet profissionalmente institucionalizada denominada Ballets Russes, oriunda da Rússia e dirigida por Diaghlev. A partir disso, em meados de 1930, ocorreu a imigração ao Brasil 
de alguns bailarinos e coreógrafos europeus e russos, disseminando assim a arte do ballet (Achcar, 1998; Sucena, 1989).

O ballet no século XIX e XX representa um projeto cultural de nacionalismo através de estilo lírico e dança fluida nas companhias, com a presença de um coreógrafo residente, com caráter de identificação do público junto às obras selecionadas pelo diretor (Wainwright, Williams, \& Turner, 2007). No mesmo estilo e estrutura do Ballets Russes, outras companhias de renome perpetuaram esse modelo, porém com algumas modificações técnicas. No Brasil, fundaram-se algumas companhias de dança nesses moldes: o Corpo de Baile do Teatro Municipal do Rio de Janeiro (1927) e o Corpo de Baile do Teatro Municipal de São Paulo (1940) (Achcar, 1998; Sucena, 1989).

Atualmente, o ballet se constitui na técnica de dança mais comercializada em todo o mundo (Wainwright \& Turner, 2004; Wulff, 2008). O ballet é a forma de dança teatral mais reconhecida nas sociedades ocidentais, propagado atualmente como uma marca global (com diferenças de estilo) pelas escolas e companhias de dança (Thomas, 2003), disseminado como um produto de uma cultura de massa e de consumo (Horkheimer, 1989), pela indústria cultural (Adorno \& Benjamin, 1975).

\section{As companhias de dança e os bailarinos}

As companhias de dança das mais diversas partes do mundo vêm, desde meados do ano 2000, assemelhando-se nos seus modos de gestão, sendo características cada vez mais presentes nestas: (a) a organização hierárquica e especializada do trabalho, (b) a transformação de coreografias e coreógrafos como produtos de ballet, (c) a reprodução de repertórios de reduzida originalidade e, simultaneamente, de grande diversidade coreográfica. Nesse contexto seus principais agentes, os bailarinos, (d) são exigidos por uma sofisticação e pluralidade técnica (corpos atléticos), (e) perdem sua liberdade artística de interpretação, (f) vivenciam rotinas intensas de trabalho, (g) aumentam o risco de lesões, (h) sofrem pressão pela manutenção de uma imagem estética de juventude, (i) apresentam a expectativa de atingir o dançar com a alma.

Uma dessas características de companhias de dança se refere à organização de seus vários profissionais em uma estrutura hierárquica bem definida - líder visionário, artistas principais e de substituição (Reed, 1998). Mais do que isso, a gestão das companhias de dança é profissionalizada, e estas possuem sindicatos de representação da classe artística, agregando uma equipe composta por aprendizes, corpo de baile, solista, primeiro bailarino, maitre de ballet, coreógrafo, diretor artístico, administradores, técnicos de luz e som, profissionais de Pilates, médicos e massagistas (Minden, 2005). Existe, além da organização hierárquica, uma divisão especializada do trabalho e uma interrelação entre cada um desses agentes, cada qual realizando uma tarefa específica no desenvolvimento dos bailarinos corpos.

Outra particularidade no modo de gestão de companhias de dança é a transformação das coreografias e dos coreógrafos em produtos de ballet. As companhias de dança atualmente comercializam, em crescente velocidade, obras coreográficas, proporcionando a troca global destas entre si. Por exemplo, royalties coreográficos cobrados pelas maiores companhias de dança da Europa e dos Estados Unidos sobre as coreografias de Forsythe, Balanchine, Kylian e Ashton ao serem dançadas por inúmeras outras companhias de ballet do mundo (Wainwright et al., 2007). Tal modelo de gestão comercial, importante destacar, ocorre em um contexto de decrescente número de tournées das companhias de dança, assim como a concentração da lucratividade naquelas proprietárias dos royalties coreográficos. Adorno e Benjamin (1975) previram esta situação ao ressaltarem que o ballet tornar-se-ia somente outra parte da indústria cultural.

Dentro desse contexto de intensa comercialização das obras coreográficas, as companhias de dança requerem exigência técnica de bailarinos para dançarem, repetidamente, repertórios de reduzida originalidade e, simultaneamente, de grande diversidade coreográfica. A escassa originalidade coreográfica, por exemplo, requer do bailarino apenas uma execução técnica perfeita (execução dos movimentos) de algo previamente coreografado (movimentação previamente elaborada). Nesse 
contexto, o bailarino perde sua liberdade de interpretação da dança (Wainwright et al., 2007), uma vez que, mais importante que a criação de um estilo, é a repetição deste.

Ao mesmo tempo em que a originalidade coreográfica está reduzida nesse contexto de comercialização global de produtos de ballet, a diversidade coreográfica em um mesmo espetáculo demonstra ser crescente. Em uma mesma temporada, os bailarinos profissionais dançam diversos estilos coreográficos, entre eles ballet, dança contemporânea e moderna (Roncaglia, 2008; Wulff, 2008). Os bailarinos transitam por esses diferentes estilos em um mesmo espetáculo, sendo requisitados em treinos para perfeita execução da técnica do ballet clássico e, simultaneamente, nos ensaios e nos espetáculos, pela busca da perfeição focada na concretização de danças que envolvem uma pluralidade técnica e artística.

Esse contexto de sofisticação e diversidade técnico-coreográfica reflete-se na forma de um forte estresse nos bailarinos, pois exige preparo para a execução de diversos repertórios com movimentos novos de seus corpos (Wainwright \& Turner, 2004). Tais expectativas de desempenho se materializam em uma exigência atlética dos corpos bailarinos, pois requerem destes uma força física e uma flexibilidade diferente - diferentes grupos musculares - daqueles usados nos ballets clássicos. Desse modo, explica-se a intensa rotina de trabalho vivenciada por bailarinos de companhias de dança profissionais, a qual envolve seis dias por semana e oito horas diárias entre treinos, ensaios e espetáculos. No ballet contemporâneo, forçar os bailarinos além do limite a partir de extensas cargas horárias, como trabalhadores de fábrica, ocorre devido às expectativas de atletismo pertinentes a essa carreira (Delinder, 2005).

Esta situação de intensa exigência acaba por se relacionar com outra faceta dessa relação companhias de dança e bailarinos: o aumento do risco de lesões. É a partir da conjuntura de prevenir essas lesões e assegurar uma maior produtividade desses bailarinos que as companhias de dança buscam moldar e tonificar esses corpos, a partir do trabalho especializado de diversos profissionais que coordenam os treinos, as dietas e as terapias de lesões em tais instituições. Os bailarinos, por sua vez, tanto aceitam (corporificam) os dispositivos de exigência e controle do seu corpo por parte das companhias de dança - dietas, condicionamento físico, tratamentos (Wainwright \& Turner, 2004); assim como associam a aceitação deste risco diário da lesão como um sinal do hábito vocacional. Ou seja, o bailarino se lesiona, sente dor, busca ignorá-la e ir ao palco interpretar um papel emocionalmente (Bourdieu, 1988).

Além das lesões, outra questão envolve a relação entre bailarinos e companhias de dança em tempos contemporâneos: uma pressão pela manutenção de uma imagem estética de juventude. Diferentemente do século passado, no qual as carreiras dos bailarinos eram mais longas, como prova Rudolf Von Laban que dançou profissionalmente até os 58 anos (Au, 1997), na sociedade atual, a carreira de um bailarino de ballet termina em torno dos 30 anos de idade (Wainwright \& Turner, 2004). Tal redução no tempo de carreira ocorre devido ao uso extremado do corpo - rotina intensa, exigência atlética, constantes lesões -, sendo esse contexto introjetado pelo bailarino, que compreende a necessidade de seu corpo ser jovem para se apresentar para a plateia, constituindo assim uma consciência sobre uma aposentadoria precoce (Roncaglia, 2008).

A par dos treinos que visam aprimorar a técnica corporal - força, resistência, rapidez e, principalmente, flexibilidade, equilíbrio e controle, outro atributo se apresenta para diferenciar os bailarinos: o dançar com a alma. O dançar com a alma significa um ponto de pico quando a ação e a consciência se fundem; estar presente, momento em que tudo se funde (Aalten, 2004); estado de transcendência, ou seja, "um estado de fluidez ou transcendência no qual os bailarinos não têm que pensar na técnica, mas se encontram criando novas zonas de arte de ballet" (Wulff, 2008, p. 525). O bailarino deve possuir em seu potencial artístico qualidades estéticas, musicalidade, habilidade para representar, presença de palco, carisma, perfazendo os requisitos do capital cultural (requisitos técnicos e artísticos) corporificado.

Os bailarinos tornam-se um dos principais agentes das companhias de dança, sendo fortemente exigidos a atingirem resultados no campo artístico. Esses resultados estão fortemente vinculados a 
uma exigência corporal, sendo os bailarinos selecionados nas companhias pelo critério de facilidade de mudança de suas corporalidades, de modo que o habitus (Bourdieu, 1988) desejado pela companhia possa ser corporificado por esses trabalhadores, ao longo de suas carreiras. Conforme analisado no decorrer desta seção, o habitus que as companhias contemporâneas desejam se refere à exigência por um bailarino atlético (Aalten, 2004; Wainwright \& Turner, 2004), que conheça os rituais de passagens das lesões (Wainwright et al., 2007), que tenha consciência da necessidade de uma imagem estética de juventude (Au, 1997; Roncaglia, 2008; Wainwright et al., 2007; Wulff, 2008) e que busque o dançar com a alma (Aalten, 2004; Wulff, 2008).

\section{Uma Etnografia Corporificada}

Com intuito de investigar as corporalidades do trabalho bailarino, escolhemos o método etnográfico recorrente em estudos socioculturais de dança (Citro, 2011; Wainwright \& Turner, 2004; Wainwright, Williams, \& Turner, 2006, 2007; Wulff, 2008), sócio-culturais sensoriais (Pink, 2009, 2011) e sócio-organizacionais com enfoque no corpo (Flores-Pereira et al., 2008; Hindmarsh \& Pilnick, 2007; Rosa \& Brito, 2010; Sinclair, 2005).

A etnografia em questão foi realizada em uma importante companhia de dança brasileira, a Dançar Companhia de Dança, pela primeira autora deste artigo (pesquisadora participante). Nessa etnografia, a pesquisadora participante privilegiou a observação da vivência (corporal) dos bailarinos em relação ao espaço, ao tempo, ao peso, à força (Mota, 2012), aos sentidos (olfato, paladar, tato, audição, visão) (Pink, 2009), ou seja, capacidades corporais cinestésicas, visuais espaciais, temporais aurais, emocionais (Harquail \& King, 2010), as quais funcionaram como um recurso metodológico primordial na obtenção de uma compreensão corporificada (Flores-Pereira et al., 2008; Hindmarsh \& Pilnick, 2007; Sinclair, 2005) e emplaced (Pink, 2011) do material de campo. Tomamos como emplacement a multisensorialidade do pesquisador/pesquisado imbricada com a vivência - social, cultural, histórica - do ambiente (Pink, 2011). Para designar essa conjuntura metodológica, adotamos a nomenclatura etnografia corporificada.

O campo etnográfico ocorreu nos meses de junho e julho de 2011. A relativa brevidade da experiência etnográfica foi compensada pela presença integral da pesquisadora participante em todos os dias e horários de trabalho da companhia de dança. Além disso, a pesquisadora participante é ela própria uma bailarina, tendo experiência com o campo do ballet e companhias de dança (brasileiras e internacionais), desde o ano de 1993. Tal experiência prévia à entrada de campo agilizou sua pesquisa tanto comportamental (integração com o grupo), quanto tecnicamente (identificação de técnicas e interpretações, por exemplo).

A Dançar possui trinta e nove bailarinos, dos quais vinte e quatro bailarinas e quinze bailarinos, com trajetórias diferentes de formação em dança como experiência profissional. $\mathrm{O}$ foco das observações e das entrevistas foram estes trabalhadores bailarinos, tendo sido importante também conhecer outros agentes da Dançar que atuam na configuração da rotina desses trabalhadores artistas. A apresentação de todos esses informantes ocorrerá a partir de nomes fictícios, havendo destaque para a origem da informação: observação ou entrevista.

As observações do campo - treino, ensaios, intervalos e dois espetáculos no Teatro Municipal da Cidade (nome fictício) - foram transpostas para um bloco de notas, sendo que, ao final do dia, a pesquisadora participante lia e transcrevia estes registros para o diário de campo, assim como elaborava uma análise inicial dos acontecimentos. No período final na Dançar, a pesquisadora participante realizou treze entrevistas (doze bailarinos e diretora artística) a partir de um roteiro semiestruturado que buscava capturar mais informações acerca das vivências corporais dos bailarinos. Tais entrevistas foram gravadas e transcritas pela própria pesquisadora participante. 
$\mathrm{Na}$ análise utilizamos o software de análise de dados qualitativos Maxqda no sentido de facilitar o agrupamento do material empírico coletado (fontes primárias) - 145 páginas de entrevistas e 112 páginas de diário de campo. O Maxqda ofereceu "recursos básicos para trabalhar com documentos online, codificação, acesso a textos, exibição de codificação e redação de memorandos" (Gibbs, 2009, p. 155), porém a construção das categorias e os conceitos que estas representam ocorreu a partir de nosso debate - as autoras deste artigo - o qual englobava as recorrências do material empírico (observação, falas êmicas em contexto de rotina, entrevistas, documentos), a retomada da literatura de base da pesquisa (corporalidade nos campos da dança e da Administração) e o intuito de constituir um texto que reconstruísse e recontextualizasse das corporalidades vivenciadas pelos bailarinos na Dançar.

\section{As Corporalidades do Trabalho Bailarino na Dançar Companhia de Dança}

Esta seção de análise foi organizada nas subseções: (a) A Dançar Companhia de Dança, da qual explanamos sobre seus modos de organização; (b) As Corporalidades do Trabalho Bailarino, da qual detalhamos três processos de corporificação dos bailarinos na Dançar.

\section{A Dançar Companhia de Dança}

Desde sua fundação, a direção da Dançar segue grande parte dos modos de organização presentes nas grandes companhias de dança da Rússia, da Europa e dos Estados Unidos. Ponzio (2008, p. 104) aponta sua semelhança com o modelo do Balé da Ópera de Paris: "Com recursos e apoio inéditos no Brasil, a [Dançar] ... projeto ambicioso, seguindo o modelo do Balé da Ópera de Paris ... companhia francesa, com 154 bailarinos, nasceu há 350 anos na corte de Luis XIV”. Começamos a tratar dessas semelhanças a partir do modo hierárquico e especializado de organização do trabalho.

$\mathrm{Na}$ Dançar, a estrutura hierárquica encontra-se composta por: duas diretoras (artística e adjunta); uma assistente de direção; uma ensaiadora; coreógrafos convidados; e um ballet master. Uma organização hierárquica também aparece na equipe de bailarinos: na base os bailarinos aprendizes; no nível intermediário, o corpo de baile; e, no topo da carreira, os solistas. A companhia possui ainda uma equipe administrativa interna, duas secretárias, equipe de audiovisual, pianista e sonoplasta, costureiras, staff operacional e faxineira; e equipe de consultoria externa (composta por personalidades intelectuais e políticas).

Um ponto importante a ser ressaltado é a prevalência do modelo de coreógrafo convidado, o qual, conforme anteriormente apresentado, vem sendo utilizado por diversas companhias de dança do mundo. Os coreógrafos convidados vêm de outras localidades (do mundo), somente para ensinar a coreografia a partir de um contrato temporário. A Dançar, não possui nenhum coreógrafo residente, sendo as diretoras, ensaiadoras e o ballet master os responsáveis pelo repasse das ideias deste coreógrafo convidado, quando ele se retira.

Junto com a escolha de trabalhar com coreógrafos convidados está a compra de coreografias royalties coreográficos - de companhias de dança dos principais centros de produção de ballet, como obras do New York City Ballet (NYCB, n.d.). A Dançar prioriza repertórios mundialmente reconhecidos, ocupando nesse mercado primordialmente o papel de importador. Uma das consequências dessa escolha é que não há produção de um estilo próprio na Dançar, ocorrendo a não formação de características de individualidade cultural, ou de uma originalidade coreográfica. Como afirma Katz (2011), na Dançar a busca de perfil próprio não parece ser prioridade.

Ressalta-se ainda na Dançar a questão da diversidade técnico-coreográfica. A diretora artística na entrevista afirma que a marca da Dançar é a diversidade, ou seja, múltiplos estilos coreográficos, como o ballet clássico, o contemporâneo e o moderno. 
A questão das extensas rotinas de trabalho, especialmente dos bailarinos, também ocorre na Dançar. Os horários e a intensidade dos treinos, ensaios e espetáculos dependem da temporada, sendo o plano de trabalho definido pela direção da companhia. De maneira geral a companhia funciona no período de segunda a sábado, das $10 \mathrm{~h}$ às $17 \mathrm{~h}$ e $40 \mathrm{~min}$, sendo domingo o dia de folga, com exceção dos dias nos quais está prevista apresentação em espetáculos. Simion, em sua entrevista, também aponta essa rotina da Dançar como "coisa puxada", analisando: "a nossa carga horária aqui é muito maior do que todas as outras companhias ... que é uma das minhas grandes brigas a nossa carga horária aqui"”.

Além de extensa, a carga horária também tem uma intensidade importante. O plano de trabalho que determina a expectativa da direção da Dançar relação às atividades a serem executadas pelos bailarinos, caracteriza-se pela organização do trabalho bailarino sem escala de folga, com um esquadrinhamento máximo do tempo (Foucault, 2002). Conforme fala de um bailarino: "essa tabela de horários com meia hora de intervalo! No que você não estava sentindo dor, passa a sentir agora" (diário de campo). O tempo de trabalho do bailarino é ainda controlado pelos relógios nas salas de ensaio, pela necessidade dos bailarinos pedirem autorização à ensaiadora para irem ao toilete, pela exigência da presença de todos os bailarinos na sala de ensaio, mesmo para aqueles que não eram escalados. Na fala da ensaiadora Damia: "não é a Tia Damia que falou, é que vocês sabem que temos que usar os bailarinos durante todo o tempo de horário ... mostrar trabalho enquanto vocês estão aqui!" (diário de campo).

Semelhante à literatura do campo da dança, a Dançar apresenta modos hierárquico e especializado de trabalho; participa do comércio dos produtos de ballet (coreografias e coreógrafos) na condição de comprador; apresenta um repertório de reduzida originalidade e grande diversidade coreográfica; assim como organiza sua rotina de trabalho (especialmente a dos bailarinos) de modo extenso (carga horária) e intenso (controle do tempo). Tanto a apresentação da literatura do campo da dança, quanto essas caracterizações na Dançar são relevantes para a próxima fase da análise, a qual se refere ao apontamento dos processos de corporificação que ocorrem com os bailarinos dessa companhia de dança.

\section{As corporalidades do trabalho bailarino na Dançar}

O bailarino constitui-se em um dos agentes principais para a existência da companhia de dança e sua carreira se desenvolve na sua interação com esta (Achcar, 1998; Anderson, 1992; Au, 1997; Minden, 2005; Roncaglia, 2008; Sasportes \& Ribeiro, 1991; Sucena, 1989). Nessa interação, os bailarinos vivenciam exigências, expectativas e pressões por parte das companhias de dança - na figura do corporativo, dos colegas, da plateia - que acabam sendo corporificadas como parte de seu trabalho bailarino.

A pesquisa de campo na Dançar nos permitiu apontar três processos de corporificação que ocorrem no trabalho de seus bailarinos: (a) a corporificação da dor; (b) a corporificação de um tipo de corpo (jovem e magro) e de uma movimentação corporal específica; (c) a dificuldade de atingir a corporalidade do dançar com a alma.

\section{Corporificando a dor}

Assim como comprovam outros estudos em bailarinos de companhias de outros países (Wainwright et al., 2006; Wainwright \& Turner, 2004; Wulff, 2008) os bailarinos da Dançar são disciplinados para interpretar e incorporar estilos de movimentação coreográfica e personagens, independente do que sintam. Nesse contexto, tais bailarinos aprendem a lidar com o cansaço físico e a sua influência no peso e na força do movimento, ao longo do seu período de execução. No ato de dançar, eles aprendem a aceitar a dor física das lesões, das marcas roxas de batidas na musculatura, do cansaço físico, em diversas partes do seu corpo como: nas costas, nas coxas, nas panturrilhas, nos pés. Esse corpo lesionado, cansado e doído torna-se parte da rotina do trabalho em um contexto de companhia de dança e acaba por ser corporificado pelos bailarinos. 
Diversos momentos de pesquisa demonstraram esse contexto, como a fala de Yago em entrevista: "Eu entro, ligo a tecla: Foda-se, e vou! Já cheguei a dançar com dedão luxado tipo roxo, enorme! Tinha que dançar! Achei que podia ficar pior, mas pior ainda é a sensação para mim de não estar em cena". E a situação de campo descrita pela pesquisadora participante:

"na companhia presenciei uma lesão quando no ensaio um bailarino puxou a solista Irlei de mau jeito e a machucou no ombro. Ela saiu de cena quando terminou a coreografia apertando o braço de dor, mas não falou nada! Logo no próximo ensaio, Irlei ensaia solo com tensor; tipoia no braço direito lesionado, dançando como se não tivesse ocorrido nada".

Essa relação entre dor, estar em cena e bastidores (coxia) aparece de maneira mais clara na seguinte nota de campo:

"No ensaio, os bailarinos permanecem na coxia - espacialmente demarcada com fitas crepe no piso transmitindo um olhar sério, de concentração na coreografia que irão executar. Nisso, um deles toca em partes do seu corpo, como a coxa, para aliviar ou auxiliar a sentir a intensidade da dor, com uma expressão tensa, e outro bailarino busca relaxar, tentando provocar uma respiração profunda e mais pausada, ambos com uma postura não tão ereta e sim mais relaxada deixando seus ombros caídos”.

No entanto, ao pisar em cena, quando a diretora comanda o início do ensaio, ou no palco quando soam os três sinais da campainha para o início do espetáculo, o bailarino corpo emite um alerta para que as percepções estejam ligadas e ativas naquele momento da dança, no sentido de esquecer a dor, deixar o suor escorrer (não se secar), não arrumar o figurino em cena, elevar o torso para frente e para cima, elevar o olhar para o horizonte longe (demonstrando uma atmosfera de superioridade), esticar todo o corpo e estar perceptivo ao que acontece no espaço, sentir a música que está sendo tocada, os sons de outros bailarinos, a fala ou a respiração do público. Nesse sentido, Simion, em entrevista, relata sua vivência dessa forma de emplacement (Pink, 2011), ao salientar que a emoção do ensaio, a introjeção do ser bailarino e vestir uma identidade de bailarino influencia na sua percepção da dor: "na hora tu não sente, esse é o problema desta profissão".

Para o bailarino, ignorar (ou aceitar) a dor está vinculado a uma possibilidade de se manter em cena, pois essa destreza de expressar corporalmente um sentimento alheio ao que efetivamente está sentindo (no caso, a dor) valoriza seu capital físico. Conforme essa destreza se desenvolve, aliada à técnica de execução dos passos, aumentam as chances desse bailarino ser escolhido para dançar papéis principais na companhia, e, de modo estratégico, ascender socialmente neste campo (Bourdieu, 1988).

Mais do que uma estratégia consciente de ignorar ou aceitar a dor, entretanto, trazemos a ideia de que o bailarino corpo aprende a se acostumar com a possibilidade diária da dor. As práticas (corporais) referentes à dor vão sendo corporificadas pelos bailarinos durante a sua vida profissional (Tarr \& Thomas, 2011), estabelecendo um habitus (Bourdieu, 1988) que os auxilia a lidar e a se acostumar com as dores particulares desse ofício. O estabelecimento desse habitus permite ao bailarino uma sensação de ser um peixe na água (Bourdieu, 1988) ao conseguir, mesmo que com dor, dançar.

\section{Corporificando um tipo de corpo e de movimentação corporal}

O ballet produz uma extensa conceituação de tipos físicos e movimentos estereotipados de talento, e aqueles que não se encaixam nesses tipos, devido à política da companhia, raramente são escalados para partes solo nas coreografias (Wulff, 2008). Esse contexto de idealização do que é ser bailarino também aporta na Dançar, uma vez que seus bailarinos buscam corporificar um tipo de corpo e de movimentação corporal (capital físico e artístico) presente nos bailarinos modelos.

A ideia de bailarinos modelos se refere aos artistas citados pelos bailarinos da Dançar como ícones da dança, geralmente famosos de companhias internacionais. Tais artistas são acessados pelos bailarinos da Dançar a partir de vídeos, aos quais assistem no intuito de investigar características físicas, técnicas e artísticas desse(s) bailarino(s) modelo(s). As características ressaltadas nesses bailarinos modelos envolvem um biotipo com pouca gordura corporal (magro), flexível, musculatura 
delineada, pernas longas, pés curvados, barriga desenhada, cintura fina, pescoço alongado, ombros colocados levemente para trás, coluna alongada, ou seja, um (bailarino) corpo capaz de passar para a plateia uma sensação de energia, velocidade, leveza, elegância, agilidade.

Nesse processo de legitimação dos bailarinos modelos, aparece uma relação especial com certas partes do corpo valorizadas na dança, focadas na estética do físico e da técnica; como requisitos para serem escolhidos como primeiro bailarino, ou reconhecidos por dançar de determinada maneira. Luana, em sua entrevista, demonstra sua idealização: "Svetlana Zaharova. Porque ela tem tudo! Ela é muito bonita, ela tem perna, pé, giros ... ela tem tudo, é uma bailarina completa, tem tudo, eu queria ser como ela". Ricardo fala de seu ideal a partir de um conjunto de bailarinos modelos:

"É o andeors (capacidade física de rotação das pernas para fora), pé perfeito, perna bonita, acho que o clássico precisa disso, não é só você chegar e falar eu danço clássico de qualquer jeito, não é bem assim. ... Mas inspirações claro, tem a Pina Bausch que eu acho incrível... tem alguns bailarinos aqui do Balé da Cidade, ... eu gosto muito do NDT, eu acho que eles já são mais velhos, são mais experientes, tem aquela coisa de tudo que eles já sofreram na vida eles jogam no palco, Pina Bausch tem aquelas mulheres incríveis de 50 anos, sabe? ... eles servem de inspiração para qualquer bailarino!” (entrevista).

Apesar de Ricardo destacar alguns bailarinos mais velhos e experientes como seu espelho, outras informações de campo demonstram que a juventude é mais valorizada do que a experiência nesse modelo globalizado de gestão de companhias de dança. Isso se percebe pelo fato da Dançar priorizar a contratação de bailarinos com vinte anos de idade, reforçando as premissas utilizadas por outras Companhias de Dança, como o New York City Ballet (NYCB, n.d.) e o Ballet Opera de Paris (Opera National de Paris, n.d.). O texto de Ponzio (2008, p. 104) fala um pouco dessa escolha na Dançar, assim como antecipa o motivador de tal ação organizacional.

“a (Dançar) exigiu técnica clássica apurada dos seus recém-contratados 36 bailarinos - 20 moças e 16 rapazes, com faixa etária que varia de 18 a 25 anos (apenas um tem 30). Tal requisito é considerado fundamental para direção, no seu projeto de formar um repertório que vai do século 19 ao 21 ”.

Assim como percebido na literatura do campo da dança, a escolha por bailarinos (corpos) jovens na Dançar ocorre em um contexto de exigência por uma técnica clássica apurada, ou da execução de um repertório diverso - que vai do século 19 ao 21. Isso afeta a identidade (uma identidade corporificada) dos bailarinos ao constituir, simultaneamente à ideia de juventude do corpo bailarino, a consciência de que bailarinos têm uma carreira curta e, consequentemente, uma aposentadoria precoce (Roncaglia, 2008). Esse contexto se refletiu em momentos de campo, por exemplo, uma conversa entre bailarinos sobre o fato de um bailarino russo famoso, com idade por volta dos cinquenta anos, querer ainda dançar: "é um absurdo ... e agora quer voltar a dançar ... com aquela idade!" (comenta Yago, 22 anos). Assim como Simion, em entrevista, também nos elucida um pouco esse contexto:

"eu percebi que tenho pouco tempo ainda para dançar ... esse tipo de dança com mais engajamento físico e tal ... não se pode fazer, não é preconceito com bailarino mais velho, mas não se pode fazer com 35 ou 40 anos esse repertório que a gente faz aqui ... eu meio constatei, eu não tenho mais muito tempo então eu quero aproveitar ... eu quero ser como o Pelé, de ter a consciência de parar na hora certa, para não fazer feio, eu já acho que com 28, eu já estou exagerando um pouco, acho que tem coisas que já começa a ficar feio".

A magreza também constitui uma parte importante da identidade (corporificada) do mundo da dança (ballet) que se estende para o contexto da Dançar. Junto com a juventude, a magreza do corpo permite a execução de um tipo de movimentação corporal idealizado e cobrado, como ilustra Mário em entrevista: "Tem que ter uma magreza considerável, principalmente para as meninas ... homem também tem que ter um porte considerável, tem que conseguir carregar (as meninas) e tal!".

Ser bailarino, deste modo, remete a uma estética de tipo de corpo e de movimento corporal padronizada, a qual é desejada nas companhias de dança de maneira mais ampla e na Dançar em especial. Essa padronização se acentua quando o estilo de dança em questão é o ballet clássico, mostrando-se aparente em expectativas corporais como juventude, magreza (especialmente para as 
mulheres) e força (especialmente para os homens), assim como a idealização de determinados movimentos corporais, sendo alguns: o pé esticado com colo de pé saliente, as pernas com linhas em $\mathbf{x}$, projeção do olhar para cima, peito empinado refletindo uma postura ereta, ser alongado (flexibilidade articular), articular o corpo com suavidade nos movimentos, ter o andeors, desenvolver musicalidade na precisão do movimento no espaço e, inclusive, puxar o peso para cima remetendo à leveza, e algumas vezes para baixo no contemporâneo, ao estar mais para o chão.

Essa expectativa se apresenta na Dançar na forma de um elenco jovem, magro, assim como nas constantes idealizações realizadas pelos próprios bailarinos em relação a bailarinos modelos. Desse modo, a identificação dos bailarinos da Dançar em relação ao trabalho bailarino ocorre a partir da corporificação das qualidades físicas disseminadas nesta profissão, assim como na sua capacidade de execução idealizada da técnica.

\section{Corporificando o dançar com a alma?}

Uma expectativa final das companhias de dança profissionais em relação a seus bailarinos se refere à capacidade destes dançarem com a alma (Aalten, 2004; Wulff, 2008). Essa sensação pode ser semelhante ao que Citro (2011) refere como gozo, um estado de alegria e emoção intensa que se alcança ao dançar. Apesar da nomenclatura dançar com a alma nos levar inicialmente a uma compreensão não corporal dessa dimensão do trabalho bailarino, afinal o termo alma tem sido culturalmente compreendido em oposição ao corpo, a abundante corporalidade pode ser vista na constituição desse ideal de dança.

O dançar com a alma é expresso e vivenciado de maneira corporal, por exemplo, na intenção do olhar e do peito do bailarino, o qual demonstra na forma e na intenção do movimento, uma projeção da sua expressão. A diretora da Dançar, ao corrigir um bailarino durante o ensaio, reforça a importância da expressão do olhar no dançar: "marca bem o foco, você tem que projetar durante o movimento" (diário de campo). Outro local do corpo, que parece marcar a postura do bailarino, é o ventre contraído, denominado o centro do bailarino, locus de controle da respiração (inspiração e expiração) durante os movimentos. O modo como o bailarino se desloca, inspirando o ar, promove na plateia uma sensação de que está elevando seu corpo para cima, e, ao caminhar na meia ponta, promove a ilusão de leveza no movimento.

O bailarino introjeta esse domínio no modo de ser e expressar seus sentimentos através do corpo, principalmente no ofício de transmiti-los ao público, à medida que vivencia tais papéis e deixa fluir essa introjeção ao dançar com a alma. Essa sensação aparece na explicação da bailarina Luana em relação ao seu corpo: "Não é que eu não me sinto, é que parece que eu estou fora do meu corpo. Parece tudo meio automático, eu não penso para levantar o braço. Eu não penso! Eu não sei, é uma sensação meio de liberdade!" (entrevista). Rita, outra bailarina, complementa:

"Olha nem todas as vezes que eu danço tenho esta sensação, mas a melhor sensação que eu tive quando eu estou dançando é que eu estou voando! Quando eu sinto que eu fui bem e saiu tudo como eu queria, é como se eu tivesse planando no ar, essa é a sensação!" (entrevista).

Essas percepções da bailarina Luana de que é algo que não se pensa, que é tudo meio automático, ou a da bailarina Rita de estar voando, planando no ar, são todas experiências corporais que estão vinculadas a um momento da execução do trabalho bailarino. Quando analisamos com foco na questão do corpo percebemos que dançar com a alma é uma corporificação que tanto valoriza o trabalho bailarino (pois valoriza o trabalho artístico da companhia), quanto se constitui em um momento especial para esses trabalhadores artistas.

O contexto atual de trabalho das companhias de dança, em especial o da Dançar, dificulta o alcance da sensação do dançar com a alma. Essa dificuldade ocorre em contextos de uma arte rotinizada e na necessidade de introjeção de uma diversidade técnica-coreográfica. A bailarina Ana Lúcia, em sua entrevista, conta como tenta fugir da sensação de arte rotinizada, buscando sensações diferentes ao dançar: 
"Quando o espetáculo é bom, eu procuro sempre fazer algo diferente com alguma intensidade ou algum sentimento para não (enjoar). A gente já tem uma arte rotinizada, então eu procuro sair disso para não ficar sempre todo o dia estacionada.... Então eu tento buscar sensações diferentes para enjoar o menos possível da obra".

Isso que Ana Lúcia denomina arte rotinizada se vincula à ideia da repetição das obras e da pouca originalidade coreográfica que caracteriza o contexto atual das companhias de dança repetidores de obras globais. Fica sob responsabilidade do bailarino ensaiar obsessivamente, memorizar e representar "da mesma maneira o espetáculo em cada noite" (Gomez-Pena, 2005, p. 218). Desse modo, torna-se difícil para a bailarina Ana Lúcia dançar com a alma, uma vez que, nesse contexto de trabalho repetitivo, o artista apresenta uma considerável perda de liberdade no que se refere ao seu processo de interpretação.

Se por um lado a transformação da dança em uma rotina pode se tornar um limitador da possibilidade do bailarino dançar com a alma a necessidade destes aprender e apresentar uma diversidade de estilos coreográficos em um mesmo espetáculo também se configura como algo que dificulta atingir essa sensação de fusão, fluidez, transcendência (Wulff, 2008). Ao bailarino da Dançar é exigido que este vista identidades tão distintas quando, por exemplo, em um mesmo espetáculo o mesmo bailarino muda da dança clássica para a contemporânea, em poucos segundos ao olhar da plateia. Para que um bailarino corporifique diferentes estilos e técnicas, existe a necessidade de fatores como tempo e acompanhamento coreográfico em treinos e ensaios para que talvez possa alcançar o dançar com a alma.

Entretanto, esta não é a realidade que acompanha o modelo atual de organização das companhias de dança. Na Dançar, especificamente, as coreografias apresentam reduzida originalidade e, por conseguinte, pouco espaço de interpretação do bailarino (repetição de obras globais); situação esta que é simultânea à exigência dos bailarinos corporificarem, com perfeição, uma variedade de estilos e técnicas de dança. Adicionam-se a esse quadro as questões da exaustiva agenda de treinos, ensaios e espetáculos - modo disciplinar de organização do trabalho (Foucault, 2002; Matos, 1984); do acompanhamento coreográfico limitado, da necessidade dos bailarinos corporificarem as dores e as lesões de seu trabalho, assim como que aceitem os limites corporais de sua carreira (idade, magreza, atletismo). Esse contexto reflete as dificuldades que o bailarino vivencia ao realizar seu trabalho, especialmente ao tentar vivenciar o estado de dançar com a alma.

\section{Discussão}

$\mathrm{Na}$ presente pesquisa, partimos do pressuposto de que o corpo bailarino é culturalmente moldado e mediado nas suas experiências corporificadas (Csordas, 1990). As experiências corporificadas de que tratamos se referem aos processos de constituição das corporalidades do trabalho bailarino ou, dito de maneira mais simples, aquilo que os bailarinos (e não apenas os bailarinos da Dançar, podemos pensar) precisam introjetar para se tornarem bailarinos em um contexto de companhia de dança.

Uma questão que alinha as três corporalidades do trabalho bailarino é a construção de um tipo de corpo que serve de base para a organização das relações entre companhias de dança e bailarinos: um corpo objeto (Dale, 2001). O corpo bailairino é pensado e tratado como um objeto, distanciado da pessoa bailarino, devendo ser moldado para atender às exigências do corporativo, do público, do mercado. É um objeto, pois não sente dor, não cansa, apresenta uma forma física estável e uma movimentação corporal tão constante e padronizada quanto uma máquina. O corpo bailarino é também objetificado quando exigido a mudar de técnica, de estilo a um simples comando da ensaiadora ou de um fechar e abrir das cortinas durante o espetáculo.

O bailarino não é imune a esse olhar objetificado, o qual acaba por se concretizar em uma exigência de fôlego, resistência, flexibilidade e força física, superior às possibilidades desse corpo 
bailarino, ou seja, uma cultura que naturaliza o uso extremo desse corpo trabalhador. Esse contexto de objetificação do corpo bailarino acaba também por dificultar um dos resultados almejados tanto pelo bailarinos em seu trabalho quanto pelas companhias de dança na sua qualificação artística: o dançar com a alma.

Estes três tipos de corporalidades percebidos na companhia Dançar ressaltam, portanto, que os corpos bailarinos são usados para gerar lucros às custas da suas dores e da sua criatividade, passando a ser apenas um objeto que dança. Esse contexto corrobora a premissa de Horkheimer (1989) do ballet como produto de uma cultura de massa e parte da indústria cultural (Adorno \& Benjamin, 1975; Wainwright et al., 2007; Wulff, 2008). Para Adorno, o modo industrial de produção se refletiu na serialização, padronização e divisão do trabalho nas obras de arte, e, com isso, o modus operandi da indústria cultural, mais tarde denominada como cultura de massa, passou a tratar da imitação como algo absoluto (Costa, Palheta, Mendes, \& Loureiro, 2003). Dentro deste cenário, encontramos o modelo de gestão atual utilizado por renomadas companhias de dança no mundo (Wainwright et al., 2007; Wulff, 2008) e inclusive na Dançar.

Desse modo, entendemos que essa discussão permita responder ao objetivo desta pesquisa ao dizer que o trabalhador bailarino corporifica seu trabalho em um contexto que inclui questões organizacionais - cultura organizacional, hierarquia, disciplina (Flores-Pereira et al., 2007; Rosa \& Brito, 2010) - e do campo no qual tal trabalho se constitui. Os modos de organização da Dançar Companhia de Dança e do campo da dança (história da dança-ballet, companhias de dança, bailarinos, indústria cultural, cultura de massa) materializam-se nas corporalidades do trabalho bailarino que, neste momento histórico, valoriza um bailarino com um tipo específico de corpo e de movimentação corporal (magro, jovem, atlético, forte, leve), exige um uso extremo desse corpo bailarino (dor, lesões), assim como trata tal corpo bailarino como um objeto a ser moldado (corpo máquina de repetição, uma contradição entre o desejo e a dificuldade de dançar com a alma).

\section{Conclusão}

Com o objetivo de investigar como os bailarinos de uma companhia de dança brasileira corporificam seu trabalho bailarino, refletimos sobre questões teóricas dos estudos de corpo no campo da Administração, adequando o método etnográfico no sentido de obter uma perspectiva corporificada do material empírico, assim como pensamos criticamente o contexto prático da gestão - companhia e campo da dança - do trabalho bailarino.

Teoricamente buscamos avançar os estudos de corpo no campo da Administração brasileira, os quais vêm trabalhando majoritariamente a partir da perspectiva do corpo como uma representação cultural. Usar exclusivamente o referencial de corpo representacional significa não ultrapassar a concepção objetificada do corpo (distanciado da pessoa), pois tal abordagem continua a se basear nas dicotomias pessoa e objeto, corpo e mente. Trouxemos, diferentemente, uma compreensão integrada do entre corpo, pessoa e mundo de modo a, pensando a partir de Dale (2001), abrir novas possibilidades de construção do conhecimento em Administração, ou seja, uma compreensão corporificada do campo da Administração.

Uma compreensão corporificada do campo do ballet nos moveu a pensar na decorrência prática dessa concepção objetificada do corpo bailarino e de seu trabalho, o qual ocorre em um contexto de extrema exigência, de uma vivência limitada da dança por esses trabalhadores artistas, assim como de uma dificuldade de se atingir o dançar com a alma. Mudar essa realidade significa, primeiramente, mudar a concepção de corpo (pessoa) a partir do qual as companhias de dança pressupõem sua organização. Enquanto a construção social de corpo seguir sendo a de corpo objeto, distanciado da pessoa bailarino - o corpo que não cansa, não se lesiona, não sente dor, não engorda, não envelhece, que repete - o uso extremo do corpo bailarino e a dificuldade de atingir o dançar com a alma continuará predominando: tanto na Dançar, quanto no campo da dança. 
Sob o ponto de vista metodológico, propomos-nos à utilização do tradicional método etnográfico, buscando compreender o trabalho bailarino a partir de sua perspectiva corporificada. Entretanto, ao se fazer uma busca de textos que pensassem a etnografia a partir de uma via não simbólica ou representacional, mas pela via da experiência corporal, pouco material foi encontrado (Pink, 2009, 2011). Buscamos, desse modo, textos que investigassem empiricamente o tema da corporalidade, buscando ler nas entrelinhas os modos de investigação privilegiados pelos pesquisadores em seus processos de interação com o campo de análise do material empírico.

Outra limitação se refere à escassa literatura sobre outros modelos de organizações do campo da dança que tratem o corpo bailarino para além dessa perspectiva de um objeto que dança e, diferentemente, promovam o dançar com a alma. Essa falta de textos, tanto sobre a perspectiva corporificada do trabalho etnográfico, quanto de diferentes modos de organização do trabalho bailarino, apresentam-se como oportunidades de pesquisas futuras no campo da Administração, bem como no da Dança.

\section{Agradecimentos}

Agradecemos à equipe da RAC por sua eficiência e cordialidade e aos dois pareceristas anônimos por seus comentários e sugestões. Somos também gratas ao CNPq que proveu auxílio financeiro à finalização deste artigo.

\section{Referências}

Aalten, A. (2004). The moment when it all comes together: embodied experiences in ballet. European Journal of Women's Studies, 11(3), 263-276. doi: 10.1177/1350506804044462

Achcar, D. (1998). Balé: uma arte. Rio de Janeiro: Ediouro.

Adorno, T., \& Benjamin, W. (1975). A obra de arte na época de suas técnicas de reprodução. Textos Escolhidos. In C. V. (Ed.), Os pensadores (Coleção XLVIII, pp. 7-34). São Paulo: Abril S.A. Cultural e Industrial.

Anderson, J. (1992). Ballet \& modern dance: a concise history. New Jersey: Dance Horizons.

Au, S. (1997). Ballet \& modern dance. Singapore: C. S. Graphics.

Bahnisch, M. (2000). Embodied work, divided labour: subjectivity and the scientific management of the body in Frederick W. Taylor's 1907 'lecture on management'. Body \& Society, 6(1), 51-68. doi: 10.1177/1357034X00006001004

Barry, D., \& Hazen, M. A. (1996). Do you take your body to work? In D. M. Boje, R. P. Gephart Jr., $\&$ T. J. Thatchenkery (Orgs.), Postmodern management and organization theory (pp. 140-153). Thousand Oaks: Sage Publications.

Bourdieu, P. (1988) La distincion-criterio y bases sociales del gusto. Madrid: Taurus.

Citro, S. (2011). La eficacia ritual de las performances en y desde los cuerpos. Ilha, 13(1), 61-93. doi: $10.5007 / 2175-8034.2011 v 13 n 1-2 p 61$

Costa, A., Palheta, A., Mendes, A. M., \& Loureiro, A. (2003). Indústria cultural: revisando Adorno e Horkheimer. Movendo Idéias, 8(13), 13-22.

Csordas, T. J. (1990). Embodiment as a paradigm for anthropology. Ethos, 18(1), 5-47. doi: 10.1525/eth.1990.18.1.02a00010 
Dale, K. (2001). Anatomising embodiment and organization theory. Basingstoke: Palgrave.

Dale, K. (2005). Building a social materiality: spatial and embodied politics in organizational control. Organization, 12(5), 649-678. doi: 10.1177/1350508405055940

Delinder, J. V. (2005). Taylorism, managerial control strategies and the ballets of balanchine and stravisnsky. American Behavioral Scientist, 48(11), 1439-1452. doi: $10.1177 / 0002764205277189$

Douglas, M. (1970). Simbolos naturales: exploraciones em cosmologia. Madrid: Alianza Editorial.

Eccel, C. S., Grisci, C. L. I., \& Tonon, L. (2010). Representações do corpo em uma revista de negócios. Psicologia \& Sociedade, 22(2), 309-317. doi: 10.1590/S0102-71822010000200011

Eltz, D. D. (2011). Corporalidades kanhgág: as relações de pessoa e corpo no tempo e espaço kanhgág (Dissertação de mestrado). Universidade Federal do Rio Grande do Sul, Porto Alegre, RS, Brasil.

Flores-Pereira, M. T. (2010). Corpo, pessoa e organizações. Organizações e Sociedade, 17(54), 417438.

Flores-Pereira, M. T. (2012). Corpo pessoa, sexo e gênero. In M. E. Freitas \& M. Dantas (Orgs.), Diversidade sexual e trabalho (pp.79-98). São Paulo: Cengage Learning.

Flores-Pereira, M. T., Cavedon, N., \& Davel, E. (2007). Explorando a dinâmica dos artefatos: a simbologia do corpo humano nas organizações. In A. P. Carrieri \& L. A. S. S. Saraiva (Orgs.), Simbolismo organizacional no Brasil (pp. 253-276). São Paulo: Atlas.

Flores-Pereira, M. T., Davel, E., \& Cavedon, N. R. (2008). Drinking beer and understanding organizational culture embodiment. Human Relations, 61(7), 1007-1026. doi: $10.1177 / 0018726708093906$

Foucault, M. (2002). Vigiar e punir. Petrópolis: Vozes.

Gibbs, G. (2009). Análise de dados qualitativos. Porto Alegre: Artmed.

Gomez-Pena, G. (2005). En defensa del arte del performance. Horizontes Antropológicos, 11(24), 199-226. doi: 10.1590/S0104-71832005000200010

Harquail, C. V., \& King, A. W. (2010). Construing organizational identity: the role of embodied cognition. Organization Studies, 31(12), 1619-1648. doi: 10.1177/0170840610376143

Hassard, J., Holliday, R., \& Willmott, H. (Orgs.). (2000). Body and organization. London: Sage.

Hindmarsh, J., \& Pilnick, A. (2007). Knowing bodies at work: embodiment and ephemeral teamwork in anaesthesia. Organization Studies, 28(9), 1395-1416. doi: 10.1177/0170840607068258

Holliday, R., \& Hassard, J. (Orgs.). (2001). Contested bodies. New York: Routledge.

Horkheimer, A. (1989). Os pensadores. São Paulo: Nova Cultural.

Katz, H. (2011, julho). Reflexão sobre serenata inacabada. O Estado de São Paulo. Recuperado de http://www.helenakatz.pro.br/midia/helenakatz71227274957.jpg

Kerfoot, D., \& Knights, D. (1996). The best is yet to come?: the quest for embodiment in managerial work. In D. L. Collinson \& J. Hearn (Orgs.), Men as managers, managers as men (pp. 78-98). London: Sage. 
Kraus, R. G., Hilsendager, S. C., \& Dixon, B. (1969). History of the dance in art and education. London: Prentice Hall.

Küpers, W. (2005). Phenomenology and integral pheno-practice of embodied well-be(com)ing in organizations. Culture and Organization, 11(3), 221-232. doi: 10.1080/14759550500204142

Matos, O. (1984). O corpo e o poder. Revista de Administração de Empresas, 24(1), 42-44.

Mauss, M. (2003). Sociologia e antropologia. São Paulo: Cosac \& Naify.

Merleau-Ponty, M. (2005). Phenomenology of perception. New York: Routledge.

Minden, E. G. (2005). The ballet companion. New York: Fireside.

Monaghan, L. F. (2002). Embodying gender, work and organization: solidarity, cool loyalties and contested hierarchy in a masculinist occupation. Gender, Work and Organization, 9(5), 504536. doi: 10.1111/1468-0432.00173

Mota, J. (2012). Rudolf Laban, a coreologia e os estudos coreológicos. Repertório, 18(1), 58-70.

New York City Ballet. (n.d.). New York City Ballet offers engaging programs for all audiences. Recuperado de http://www.nycballet.com/ticket_info/closeup/ep-close-up-programs.html

Opera National de Paris. (n.d.). Jeune public: tout public et scolaires. Recuperado de http://www.operadeparis.fr/en/Saison_2011_2012/Jeune_Public/index.php

Pereira, S. J. N., \& Ayrosa, E. A. T. (2012). Corpos consumidos: cultura de consumo gay carioca. Organizações e Sociedade, 19(61), 295-313. doi: 10.1590/S1984-92302012000200007

Pink, S. (2009). Doing sensory etnography. London: British Library.

Pink, S. (2011). From embodiment to emplacement: re-thinking competing bodies, senses and spatialities. Sport, Education and Society, 16(3), 343-355. doi: 10.1080/13573322.2011.565965

Ponzio, A. F. (2008, agosto). A OSESP da dança. Revista Bravo, 11(132), 104-106.

Reed, A. S. (1998). The politics and poetics of dance. Annual Review of Anthropology, 27, 503-532. doi: 10.1146/annurev.anthro.27.1.503

Roncaglia, I. (2008). The ballet dancing profession: a career transition model. Australian Journal of Career Development, 17(1), 50-59. doi: 10.1177/103841620801700108

Rosa, A. R., \& Brito, M. J. de (2010). "Corpo e Alma" nas Organizações: um estudo sobre dominação e construção social dos corpos na organização militar. Revista de Revista de Administração Contemporânea, 14(2), 194-211. Recuperado de http://www.scielo.br/pdf/rac/v14n2/v14n2a02.pdf. doi: 10.1590/S1415-65552010000200002

Sasportes, J., \& Ribeiro, A. P. (1991). History of dance. Lisboa: Imprensa Nacional - Casa da Moeda.

Sinclair, A. (2005). Body and management pedagogy. Gender, Work and Organization, 12(1), 89-104. doi: 10.1111/j.1468-0432.2005.00264.x

Sthyre, A. (2004). The (re)embodied organization: four perspectives on the body in organizations. Human Resource Development International, 7(1), 101-116. doi: $10.1080 / 1367886032000150578$

Sucena, E. (1989). A dança teatral no Brasil. Rio de Janeiro: Ministério da Cultura, Fundação Nacional de Artes Cênicas. 
Tarr, J., \& Thomas, H. (2011). Mapping embodiment: methodologies for representing pain and injury. Qualitative Research, 11(2), 141-157. doi: 10.1177/1468794110394067

Thomas, H. (2003) The body, dance and cultural theory. Nottingham: Palgrave Macmillan.

Trethewey, A. (1999). Disciplined bodies: women's embodied identities at work. Organization Studies, 20(3), 423-450. doi: 10.1177/0170840699203003

Víctora, C. G. (1999). A "mãe do corpo" dentro do corpo da mãe: um estudo sobre relações e espaço corporal em grupos populares de Porto Alegre (Cadernos do NUPACS). Porto Alegre: Núcleo de Antropologia do Corpo e Saúde, Universidade Federal do Rio Grande do Sul.

Wainwright, S. P., \& Turner, B. S. (2004). Epiphanies of embodiment: injury, identity and the balletic body. Qualitative Research, 4(3), 311-337. doi: 10.1177/1468794104047232

Wainwright, S. P., Williams, C., \& Turner, B. S. (2006). Varieties of habitus and the embodiment of ballet. Qualitative Research, 6(4), 535-558. doi: 10.1177/1468794106068023

Wainwright, S. P., Williams, C., \& Turner, B. S. (2007). Globalization, habitus, and the balletic body. Cultural Studies Critical Methodologies, 7(3), 308-325. doi: 10.1177/1532708606295652

Wulff, H. (2008). Ethereal expression: paradoxes of ballet as a global physical culture. Etnography, 9(4), 518-535. doi: 10.1177/1466138108096990

Yakhlef, A. (2010). The corporeality of practice-based learning. Organization Studies, 31(4), 409-430. doi: $10.1177 / 0170840609357384$ 